\title{
DIFFERENCES OF GENERALIZED COMPOSITION OPERATORS BETWEEN BLOCH TYPE SPACES
}

\author{
WEIFENG YANG, YiPING LUO AND XiAngling ZHU
}

Abstract. Let $\varphi$ and $\psi$ be analytic self-maps of the open unit disk $D$. Using pseudo-hyperbolic distance $\rho(\varphi, \psi)$, we characterize the boundedness and compactness of the differences of generalized composition operators

$$
\left(C_{\varphi}^{g}-C_{\psi}^{h}\right) f(z)=\int_{0}^{z}\left[f^{\prime}(\varphi(\xi)) g(\xi)-f^{\prime}(\psi(\xi)) h(\xi)\right] d \xi, \quad z \in D
$$

between two Bloch-type spaces on $D$. The results generalize the corresponding results on the single generalized composition operator and on the differences of generalized composition operators on the Bloch space.

Mathematics subject classification (2010): Primary 47B38; secondary 30H30.

Keywords and phrases: Generalized composition operator, pseudo-hyperbolic distance, Bloch type space.

\section{REFERENCES}

[1] J. Bonet, M. Lindström AND E. Wolf, Differences of composition operators between weighted Banach spaces of holomorphic functions, J. Austra. Math. Soc. 84 (2008), 9-20.

[2] C. Cowen And B. MacCluer, Composition Operators on Spaces of Analytic Functions, Studies in Advanced Math., CRC Press, Boca Raton, 1995.

[3] J. DAI AND C. OUYAng, Differences of weighted composition operators on $H_{\alpha}^{\infty}\left(B_{N}\right)$, J. Inequ. Appl. Vol. 2009, Article ID 127431, (2009), 19 pages.

[4] T. Hosokawa And S. OHno, Differences of composition operators on the Bloch spaces, J. Operator Theory 57 (2007), 229-242.

[5] S. LI, Differences of generalized composition operators on the Bloch space, J. Math. Anal. Appl. 394 (2012), 706-711.

[6] S. Li AND S. STEVIĆ, Generalized composition operators on Zygmund spaces and Bloch type spaces, J. Math. Anal. Appl. 338 (2008), 1282-1295.

[7] S. Li AND S. STEVIĆ, Products of Volterra type operator and composition operator from $H^{\infty}$ and Bloch spaces to the Zygmund space, J. Math. Anal. Appl. 345 (2008), 40-52.

[8] S. Li And S. Stević, Products of composition and integral type operators from $H^{\infty}$ to the Bloch space, Complex Variables and Elliptic Equations 53 (2008), 463-474.

[9] S. Li AND S. STEVIĆ, Products of integral-type operators and composition operators between Blochtype spaces, J. Math. Anal. Appl. 349 (2009), 596-610.

[10] S. Li AND S. STEVIĆ, On an integral-type operator from iterated logarithmic Bloch spaces into Bloch-type spaces, Appl. Math. Comput. 215 (2009), 3106-3115.

[11] J. Moorhouse, Compact differences of composition operators, J. Funct. Anal. 219 (2005), 70-92.

[12] P. Nieminen, Compact differences of composition operators on Bloch and Lipschitz spaces, Comput. Method Funct. Theory 7 (2007), 325-344.

[13] J. Shapiro, Composition Operators and Classical Function Theory, Springer-Verlag, New York, 1993.

[14] S. STEVIĆ, Generalized composition operators from logarithmic Bloch spaces to mixednorm spaces, Util. Math. 77 (2008), 167-172. 
[15] S. Stević, On Lipschitz and $\alpha$-Bloch spaces on the unit polydisc, Studia Sci. Math. Hung. 45 (2008), 361-378.

[16] S. STEVIĆ, On an integral operator between Bloch-type spaces on the unit ball, Bull. Sci. Math. 134 (2010), 329-339.

[17] S. STEVIĆ AND S. UEKI, Integral-type operators acting between weighted-type spaces on the unit ball, Appl. Math. Comput. 215 (2009), 2464-2471.

[18] S. STEVIĆ, On an integral operator from the Zygmund space to the Bloch-type space on the unit ball, Glasg. J. Math. 51 (2009), 275-287.

[19] S. STEVIĆ, Products of integral-type operators and composition operators from the mixed norm space to Bloch-type spaces, Siberian Math. J. 50 (2009), 726-736.

[20] S. STEVIĆ, Integral-type operators from a mixed norm space to a Bloch-type space on the unit ball, Siberian Math. J. 50 (2009), 1098-1105.

[21] S. STEVIĆ, On an integral-type operator from logarithmic Bloch-type spaces to mixed norm spaces on the unit ball, Appl. Math. Comput. 215 (2010), 3817-3823.

[22] S. STEVIĆ, On some integral-type operators between a general space and Bloch-type spaces, Appl. Math. Comput. 218 (2011), 2600-2618.

[23] S. SteVić And Z. JiAng, Compactness of the differences of weighted composition operators from weighted Bergman spaces to weighted-type spaces on the unit ball, Taiwanese J. Math. 15 (2011), 2647-2665.

[24] W. Yang And X. Meng, Generalized composition operators from $F(p, q, s)$ spaces to Bloch-type spaces, Appl. Math. Comput. 217 (2010), 2513-2519.

[25] K. ZHU, Bloch type spaces of analytic functions, Rocky Mountain J. Math. 23 (1993), 1143-1177.

[26] X. ZHU, Generalized composition operators and Volterra composition operators on Bloch spaces in the unit ball, Complex Variables and Elliptic Equations 54 (2009), 95-102.

[27] X. ZHU, Generalized composition operators from generalized weighted Bergman spaces to Bloch type spaces, J. Korean Math. Soc. 46 (2009), 1219-1232. 